\title{
Um olhar possível sobre a violência simbólica
}

\author{
Lorena Karla Costa Bezerra ${ }^{1}$ \\ Rodrigo José Fernandes de Barros ${ }^{2}$
}

\section{Resumo:}

Este artigo discute, a partir de uma posição crítica, o conceito de violência simbólica do sociólogo francês Pierre Bourdieu (1983; 1989; 2001; 2002; 2015). Perseguimos este objetivo, primeiramente, refletindo sobre a violência lato sensu, nas mais diversas abordagens científicas, em um diálogo com os autores escolhidos, que nos ajudam a pensar este fenômeno e, em seguida, na discussão propriamente dita do conceito bourdieusiano. Nossa perspectiva teórico-metodológica amparou-se no materialismo histórico-dialético como utilizado pela socióloga marxista Heleieth Saffioti (2004). Em suma, pudemos ampliar a definição da violência simbólica com a consideração da ação do estigma devolvido àqueles que resistem à dominação simbólica.

Palavras-chave: violência simbólica; estigma; violência.

\section{A possible look at symbolic violence}

\section{Abstract:}

This article seeks to discuss critically the concept symbolic violence coined by the french author Pierre Bourdieu (1983; 1989; 2001; 2002; 2015). Thus, first of all, we think about the violence lato sensu through the dialogue with the chosen authors in many scientific fields. In following, we discuss properly the bourdieusan concept. Our theoretical and methodological perspective is the historical and dialectial materialism as used by marxist sociologist Heleieth Saffioti (2004). Synthetically, we have could amplify the symbolic violence's definition considering the ideological agency of the stigma against those who resist to symbolic domination.

Key words: symbolic violence; stigma; violence.

\footnotetext{
1 Mestranda pela Universidade Federal do Rio Grande do Norte (UFRN). E-mail: l.bezerra1900@gmail.com.

2 Mestrando pela Universidade Federal do Rio Grande do Norte (UFRN). E-mail: rodjfb@gmail.com.
} 


\section{Introdução}

No presente estudo, temos como principal objetivo discutir o conceito de violência simbólica, cunhado pelo sociólogo francês Pierre Bourdieu, a partir das reflexões teóricas suscitadas pela leitura de três coletâneas de textos do autor, quais sejam: Economia das trocas simbólicas (2015), o Poder simbólico (1989) e Esboço de uma teoria da prática (1983), bem como de duas das suas obras, Meditações pascalianas (2001) e Dominação masculina (2002), informadas e complementadas por artigos de comentadores. No entanto, para que pudéssemos realizar esta tarefa, nos foi necessário antes refazer os caminhos que nos levam à compreensão do que é a violência lato sensu.

Para tanto, escolhemos, no tópico seguinte, algumas das mais importantes abordagens dedicadas ao tema, que a nosso ver nos auxiliam a pensar o fenômeno da violência. O spectrum da discussão perpassa áreas tão diversas como a etologia animal, antropologia, psicanálise, filosofia e sociologia, embora privilegiando inevitavelmente os enfoques concedidos pelas ciências humanas, tendo em vista o nosso lastro de formação.

Destarte, costuramos ao longo do texto a nossa visão sobre a violência a partir do diálogo com os autores escolhidos. Diálogo tolhido, no entanto, sob um modus operandi sintetizador das contribuições de pensamentos, muitas vezes, aparentemente antagônicos como aqueles rubricados sob os rótulos de "subjetivistas" e "objetivistas".

Pensamos que essas contradições aparentes são solucionadas pelo recurso metodológico do materialismo histórico-dialético tal como utilizado pela socióloga marxista Heleieth Saffioti (2004). Queremos dizer: levando em conta a interdependência entre processos micro e processos macro, bem como entre "ideologia" e bases materiais sem, no entanto, advogar uma hierarquia necessária entre estrutura e superestrutura.

Não pretendemos, contudo, esgotar o tema, mas esboçar uma análise que poderá nos subsidiar no futuro em uma investigação mais exaustiva. De qualquer maneira, acreditamos que nos foi possível lançar um olhar mais amplo sobre o objeto de estudo, que nos permitiu provocar uma pequena abertura no conceito de violência simbólica como pensado no último tópico, demonstrando que o mesmo possui limitações e potencialidades que não podem mais ser ignoradas por aqueles que se dedicam ao assunto. Feitas tais observações, estamos agora em condições de perseguir respostas para o que é a violência. 


\section{Sobre o conceito de violência}

A palavra "violência" é etimologicamente derivada do latim violentia, que significa violência, caráter violento ou bravio, força. $\mathrm{O}$ verbo violare, por sua vez, está relacionado à ideia de tratar com violência, profanar ou transgredir. Os dois termos, no entanto, devem ser remetidos à vis, cuja significação mais profunda aponta para a força em ação, o recurso de um corpo para exercer sua força e, por esta via, sua potência, seu valor ou força vital.

Ao passo que nos aproximamos desse núcleo de significado, descobrimos que o julgamento moral desaparece para dar lugar a uma noção que designa uma força não qualificada, que apenas se torna violência quando "passa da medida" e perturba a ordem. O que está assim em jogo na própria origem etimológica e os usos correntes da palavra é a tendência a identificar o violento com atos de agressão e maus tratos ligados intimamente à transgressão de certas normas definidas socialmente (MICHAUD, 2001, p. 8).

Estas normas ou regras sociais, carregadas de historicidade, possuem grande variação, conforme o lugar e a época. Basta pensarmos como a nossa "sensibilidade" modificou-se a respeito do que é percebido como violento com o decorrer do processor civilizador (ELIAS, 1996), ao longo do qual a violência se tornou, em certa medida, monopólio do estado. De início, como a função primordial do estado era tão-somente defender a propriedade privada e a integridade física dos sujeitos, a definição restringia-se aos atos físicos de agressão a outrem e a violação a seus patrimônios (MICHAUD, 2001).

Importantes mudanças jurídicas foram conquistadas, sobretudo no século XIX e XX, segundo Michaud (2001), na legislação francesa, análogas àquelas que aconteceram em muitas outras democracias ocidentais. Lutas e embates reformaram e ampliaram o pano de fundo da compreensão do conceito para que fosse possível abarcar a violência psicológica, que embora não necessariamente transforme-se em atos de agressão diretamente físicos, tem potencial para romper não somente a integridade mental, mas também para adoecer os corpos de suas vítimas por meio dos processos de somatização das doenças psíquicas.

Entretanto, se quisermos compreender, de fato, o que é este fenômeno, cientificamente, devemos ultrapassar tanto as concepções do senso comum como as definições jurídicas também variáveis de acordo com as constituições em vigor em cada país. O que propomos aqui é pensála (a violência), ao mesmo tempo, como modelada pela cultura e ativada já no cerne mesmo do fundo orgânico da espécie humana. A fim de 
escaparmos das oposições simples geradas quer pelo "essencialismo" social quanto biológico3.

Do ponto de vista da "natureza", é lugar-comum compreender a agressividade como uma "força" ou um "instinto natural" imprescindível para a evolução da espécie ${ }^{4}$, no entanto, esta agressividade pode tornar-se agressão ou encontrar na cultura uma fonte de potencialização inédita no domínio exclusivo da fisiologia humana através das invenções tecnológicas, que aumentam seu poder de destruição (MICHAUD, 2001). Também não é de raro encontrar disseminada a visão freudiana de que caberia à cultura, ou à civilização, controlar os impulsos agressivos ou impensados dos seres humanos, o que acabaria por gerar um mal-estar (FREUD, 2010).

No entanto, ao atribuirmos à cultura ou ao estado o papel de inibir a violência aberta (este último responsável pela violência legítima), nos esquecemos de que a própria cultura pode oferecer instrumentos de conhecimento e tecnológicos para aperfeiçoá-la ou o estado de servir-se de sua autoridade para cometer genocídios em massa, sob a égide estrutural do racismo de estado, e controlar/gerir a vida e a morte de nossos corpos, enquadrados e classificados em categorias sociais, a exemplo daquelas que aparecem nas estatísticas, através do tipo de poder que Michel Foucault (2014; 2017) descreveu como "biopolítica."

Esta observação, de que a violência tem um caráter efetivamente estrutural, amparada pelos aparelhos de estado, combina com a definição dada por Michaud (2001), que a desvencilhou da noção do senso comum segundo a qual a violência está relacionada unicamente com atos individuais. Ele propõe que pensemos este fenômeno como resultado não somente de atos subjetivos, entre um agressor e uma vítima, mas de "estados" em que contribuem instituições sociais, máquinas administrativas e burocráticas capazes de romper não apenas a integridade psíquica, moral e física dos sujeitos, mas também os prejudicar em suas participações simbólicas e culturais. Trata-se de certa racionalização da violência com todos os seus mecanismos de controle e de incitação presente na própria ordem social e orientada para sua reprodução.

Conhecemos muito bem a existência de instituições como o sistema judiciário e a polícia e reconhecemos como sua finalidade garantir a ordem e controlar a violência, que associamos a atos criminosos (MICHAUD, 2001). Não pensamos que haja, além desse tipo de mecanismo, outros cuja

3 Compreendemos o fenômeno da violência como resultado de processos dialéticos entre natureza e cultura. Portanto, como destaca a socióloga Heleieth Saffioti (2004), é necessário escapar das visões simplistas que essencializam tanto a cultura quanto a natureza, impossibilitando qualquer tipo de diálogo dos saberes.

4 Por exemplo, nos estudos de etologia animal, que empregam uma compreensão evolucionista da agressividade como necessária à sobrevivência das espécies (MICHAUD, 2001) 
intenção seja, ao contrário, promover estados violentos na sociedade, presentes, até mesmo, nas mesmas instituições incumbidas de eliminá-los. A mesma força policial, que tende a atrair personalidades autoritárias para seu exercício, é responsável por várias espécies de abuso de autoridade, bem como mortes desnecessárias.

A mídia, por seu turno, participa desse processo, tornando a violência, ao mesmo tempo, banalizada e superestimada, à medida que esta aparece, de um lado, como produto vendável que incute medo e sensação de insegurança em grandes proporções e, de outro, como recorte cenográfico desprovido de carne e sangue, além de oferecer, por meio da retórica adotada, uma justificação moral para a violência do estado ou entre estados, que sequer é percebida enquanto tal, pois legitimada (MICHAUD, 2001). Como é o caso da guerra contra o terror justificada como ações antiterroristas para proteger o ocidente dos fundamentalistas islâmicos (ŽIŽEK, 2014).

No plano das relações internacionais, as nações lutam para ter um arsenal bélico potente, em que as indústrias armamentistas contribuem para criar tecnologias de destruição em massa cada vez mais ameaçadoras. No entanto, essas formas de violência praticadas com equipamentos sofisticados como mísseis e drones, que permitem ser lançados a uma enorme distância, gozam de uma legitimidade, que a violência corpo-acorpo não desfruta (MARTUCELLI, 1999).

Chamayou (2015) demonstra como a tecnologia do drone, pioneiramente utilizada pelos Estados Unidos e Israel, "projeta poder sem projetar vulnerabilidade" ao anular a relação de reciprocidade que se estabelece entre os adversários. Ao ser operado à distância, o drone poupa "a vida dos combatentes", de onde extrai parte de sua legitimidade e justificação moral, e identifica o seu alvo, o suposto inimigo, por meio de logaritmos que se baseiam em "padrões de vida" (patterns of life). Este artefato técnico tem em sua própria materialidade implicações para a estrutura de intersubjetividade envolvida na guerra. Na verdade, a própria guerra perde seu sentido, enquanto implicada no reconhecimento mútuo entre adversários. Trata-se mais propriamente de uma caça ou de um abate que revela a profunda assimetria na "relação" entre a nação que ataca e a nação atacada sem chance de defesa.

A “dronização" é uma tendência que radicaliza e realiza o desejo de aniquilar qualquer sinal de vulnerabilidade. Dessa forma, não encontra resistência dentro dos limites internos da nação portadora da tecnologia, porque resolve o impasse de obrigar os cidadãos a irem para a guerra, tornado desnecessário e, ao mesmo tempo, o estado, realizando suas ações e atos de violência, muitas vezes, designados e justificados como 
antiterrorista, fora do espaço de jurisdição nacional, permanece imune à punição e à responsabilização pelos crimes cometidos.

Os cidadãos, ao serem poupados de presenciar os desastres da "guerra", longe do alcance de seu campo de visão, podem também se tornar indiferentes a seus efeitos, bem menos onerosos do ponto de vista social e econômico para si mesmos. Esta neutralização dos aspectos negativos da guerra é redobrada pela justificação moral da pretensa necessidade desta ofensiva para resguardar a segurança nacional.

Está ainda aberta, porém a questão, saindo do rol das relações entre estados, e concentrando-se, mais microscopicamente, no nível "local", "intrasubjetivo" e intersubjetivo da violência, sobre as motivações ou pulsões que a animam antes de se tornar uma expressão belicista do confronto entre nações. René Girard (1970) oferece uma resposta, em $A$ Violência e o Sagrado, desvelando uma dimensão que pertence ao reino da subjetividade: a esfera psicanalítica que conecta o desejo à violência. Nós, segundo ele, enquanto seres desejantes, sempre procuramos modelos para o nosso desejo, desejamos, pois, por imitação. Fenômeno, que se chama mimesis. Essa disposição é uma fonte potencial de conflito, quando desejamos o mesmo objeto que o outro e estamos dispostos a competir pelo nosso objeto de desejo. O modelo pode muito bem ser outro sujeito que admiramos, passamos a desejar suas qualidades, o que sem muita dificuldade transforma-se em inveja, rivalidade e embate.

As sociedades ditas primitivas, tais como as da antiguidade clássica, dispunham de ritos sacrificiais, como mecanismo de canalização da violência para que o ciclo interminável de vingança pudesse ser quebrado. Estes ritos consistiam em eleger uma vítima substituta, um ser humano ou um animal que desviasse a violência do seu alvo real. Uma violência sagrada que daria fim a uma violência profana e interminável.

Tratava-se então de verdadeiro exorcismo com uma função social bastante definida, não obstante pouco clara para os que a realizavam. Em geral, quando a vítima era humana, escolhia-se um indivíduo que não participasse plenamente daquela sociedade. Por exemplo, um marginal, uma prostituta ou uma criança (esta última por não estar ainda plenamente socializada). Quando um animal, tentava-se o máximo possível para que lembrasse minimamente a vítima real.

No entanto, as sociedades modernas (GIRARD, 1970) não dispõem de sacrifícios rituais como mecanismos de controle da violência. O que elas possuem é um sistema judiciário, cujo efeito exorcizante pode ser questionado. A vingança que os parentes da vítima procuram na "justiça" não é satisfeita. Por estranha ironia, não nos sentimos representados por um sistema sem carne e sem osso operado mediante procedimentos burocráticos. Não somos nós, enquanto vítimas, que participamos da 
sanção e do ato violento, uma vez que a violência legítima se tornou monopólio do estado. O tal ciclo de vingança logo não se encontra rompido, portanto, os indivíduos procuram ou tendem a procurar outras válvulas de escape para o seu "desejo" de violência, o que explicaria então segundo Girard (1970) a existência de práticas como o linchamento.

Talvez possamos, a partir desse pensamento, supor que haja certa necessidade de violência no ser humano. Necessidade sobre a qual podemos nos indagar até que ponto é produzida pela cultura e até que ponto tem fundo natural, ou ainda se é mesmo pertinente estabelecer limites entre a natureza e a cultura, uma vez que há reverberações entre uma e outra. Sabemos o como a cultura molda a natureza e chega mesmo a transformá-la dramaticamente. Mais uma vez, esta necessidade de violência, seja oriunda de uma pulsão própria ou de uma pulsão derivada do desejo, e a segunda opção parece ser a de Girard, nos leva constantemente a buscar vítimas expiatórias.

Podemos, então, dizer, a partir de Girard (1970), que os conflitos sociais em torno de um objeto de desejo, com potencial para se transformar em atos de violência, são arrancados do controle direto dos sujeitos envolvidos e ganham expressões institucionalizadas e, até muitas vezes, esvaziadas de seu conteúdo particular pela força de categorizações abstratas, na forma da lei jurídica e da burocracia. Mas longe de se apresentar uma domesticação absoluta das paixões e de desejos que levam à violência, esta tentará encontrar brechas e válvulas de escape costumeiramente na figura de bodes expiatórios reforçada pela tendência de somente identificá-la com a ação de sujeitos particulares, que se tornam, nas fantasias persecutórias, os agentes onipresentes de toda a nossa desgraça.

É patente a nossa percepção da violência como uma quebra da ordem ou ruptura da normalidade, contida na origem mesma da palavra, e não enxergamos como faz parte da própria ordem como são exemplos: a violência do estado, a força policial ou a produção de miséria em larga escala como efeito de uma economia global capitalista. Entendemos como já dito, que a violência é produzida por um agente humano específico, produto de uma ação individual. Quando, na verdade, ela pode estar presente em um estado de coisas. Por conta disso, o filósofo e teórico social Slavoj Žižek distingue essas duas espécies de violência, a subjetiva e a objetiva de maneira que podemos denominar como contra intuitiva.

Enquanto empresa coletiva, segundo Žižek (2014), a violência de natureza objetiva é quase impossível de ser reconhecida no meio da multidão de agentes e instituições envolvidas, restando pouca imagem para um único culpado que unifique a totalidade. É uma violência gerada para a manutenção da ordem estabelecida, seja sistêmica ou simbólica. Já 
a violência subjetiva é a violência que facilmente se atribui a um agente, como um roubo ou uma agressão entre indivíduos - não se enxerga ação de instâncias superiores, complexas ou coletivas; o que cabe nesta imagem é a figura clara de um sujeito provido de escolhas que resolve agir pelos próprios interesses.

Não é à toa que as questões que envolvem os crimes cotidianos são, muitas vezes no senso comum, associadas a ações individuais de sujeitos desprovidos de senso moral, excluindo-se assim as possibilidades de se procurar compreender que outros aspectos mais complexos acabam por contribuir para a instauração do crime em si.

O que Žižek (2014) conceitua como "violência objetiva" - esta que é gerada pelo status quo e para a sua manutenção - pode ser mais bem compreendido, do ponto de vista genético, pela violência inaugural e o esforço repetitivo para dissimulá-la, que funda as bases do estado de direito e de sua soberania. A usurpação do poder é a verdade fundadora que deve ser recalcada e que as filosofias do contrato social têm por função esconder.

O estado assim aparece como a instância legitimadora de todas as outras, como o fundamento primeiro, arbitrário, que, no entanto, permanece intocado, não questionado, à maneira de um "intuitus originarium divino" a que se refere Bourdieu (2001, p. 113) e como o responsável pela violência simbólica legítima, o lugar por excelência do nomos, capaz de tornar realidade aquilo que nomeia.

\section{Sobre o conceito de violência simbólica}

Pierre Bourdieu (1983) foi um sociólogo francês bastante preocupado em resolver algumas das contradições mais persistentes no campo erudito, dentre as quais, podemos destacar aquelas entre indivíduo e sociedade e estrutura e agência. Ele desenvolveu assim o que considerou como uma terceira via, o conhecimento praxiológico, abordagem capaz de superar as dicotomias artificiais geradas pelas análises fenomenológicas, de um lado, que atribuía primazia ao sujeito, e do outro, pelo estruturalismo, que negligenciava o papel ativo dos agentes na construção do mundo social.

Sua teoria da prática (1983, p.6o), dessa forma, pretendia captar o duplo movimento de interiorização da exterioridade e exteriorização da interioridade. Dialética na qual os agentes incorporam as estruturas sociais das quais eles mesmos são o produto, logo transformadas em estruturas cognitivas, as quais, por sua vez, são devolvidas ao espaço social por meio da construção de estruturas objetivas correspondentes àquelas estruturas subjetivas. É em razão dessa propriedade de redundância e de 
conformidade entre estruturas sociais e cognitivas, que Bourdieu $(1983,2001)$ diz que a ordem social tende à histerese, isto é, à inércia e à reprodução.

Em outras palavras, os sistemas simbólicos (BOURDIEU, 1983, 1989,2002) (arte, ciência, religião) funcionam como estruturas estruturadas incorporadas e pré-dispostas a funcionar como estruturas estruturantes, isto é, princípios de construção do mundo social, geradores de ações e representações que têm como fundo a doxa, conjunto de pressupostos tácitos, não questionados, que escondem a verdade do arbitrário cultural e, dessa forma, eternizam e naturalizam o que, de fato, é histórico, e assim elevam a ordem social à ordem natural e cosmológica.

A incorporação da doxa, isto é, do senso comum, permite a conformidade lógica com o mundo assim construído e a comunicação com outros agentes portadores dos mesmos princípios de visão e de divisão. Para além da função de comunicação, contudo, esses princípios que instituem a divisão social e a visão correspondente cumprem uma notória função política:

\footnotetext{
Enquanto instrumentos estruturados e estruturantes de comunicação e de conhecimento que os sistemas simbólicos cumprem a sua função política de instrumentos de imposição e de legitimação da dominação que contribuem para assegurar a dominação de uma classe sobre outra (violência simbólica) dando o reforço da sua própria força às relações de força que as fundamentam e contribuindo assim, segundo a expressão de Max Weber, para a domesticação dos dominados. (BOURDIEU, 1989, p. 11).
}

Os princípios de visão e de divisão, que garantem a dominação de uma classe sobre a outra, são aqueles que dividem a sociedade entre dominantes e dominados e instituem e legitimam essa desigualdade como expressão de uma diferença ontológica, de uma hierarquia ancorada na própria natureza das coisas. Mas a condição para o dominado a aderir a uma lógica que o sujeita se assenta no desconhecimento do arbitrário e, portanto, no reconhecimento da ordem social como ordem natural. Esta sujeição é adquirida à custa de um longo processo de aprendizagem, iniciado ainda na primeira infância, através do qual o sujeito incorpora os sistemas simbólicos e os princípios dominantes que lhes são subjacentes.

O habitus (BOURDIEU, 1983; 2001; 2015) aparece aqui como um conceito fundamental de mediação e articulação pelo qual o autor estabelece a relação entre o agente e a sociedade. O habitus é uma matriz geradora de disposições práticas, duravelmente incorporadas, mais ou menos conscientes, em estado pré-reflexivo, que nos orientam em nossas ações e escolhas no espaço e nos jogos sociais. Funciona assim na forma de uma lógica prática, não refletida, e que diz respeito às posições relativas ocupadas na sociedade e assumida nos mais distintos campos sociais, que 
constituem o mundo social, como aqueles que se referem à igreja, à escola etc. dos quais o sujeito participa, bem como da trajetória social e da história, ao mesmo tempo, singular e coletiva que o acompanha.

O habitus (BOURDIEU, 2001) conta com o suporte biológico dos nossos corpos e de seu funcionamento regular como pré-condição. A tendência para antecipar o futuro com base em experiências passadas, por meio de respostas imediatas, orientadas por esquemas prévios, parece ser uma capacidade adquirida durante a história da espécie (filogênese) e comum a todos os seres humanos, isto é, a própria capacidade para adquirir e formar habitus. Em se tratando da história pessoal, no plano da ontogênese, é no ambiente familiar que formamos nosso habitus originário, o qual se transformará, por meio de uma alquimia das pulsões originárias, em habitus específicos pertinentes à inserção do indivíduo em cada campo particular.

Os campos sociais possuem autonomia relativa e seu próprio sentido do jogo e móveis de luta (BOURDIEU, 2001), cada qual tendendo a definir os seus próprios capitais, que estão em disputa, como mais legítimos e desejáveis. Existem lutas simbólicas pelas quais os agentes buscam acumular o capital em jogo5. Dessa forma, naqueles campos em que o capital cultural constitui o principal móvel de luta, como no campo intelectual, este é representado e desejado como mais vital e importante para seus membros do que o capital econômico.

A autonomização de campos como o econômico, o político, o religioso e o cultural constitui sua independência relativa (não absoluta) em face às determinações externas, abrindo espaço para a configuração de suas lógicas específicas. O campo cultural sendo mais independente das constrições econômicas, por exemplo, do que o político. No entanto, todos eles estão estruturados segundo princípios de visão e divisão, que instauram uma cisão entre dominantes e dominados. Dessa forma, a cada qual cabe uma parcela no trabalho de dominação simbólica e de reprodução material da ordem estabelecida.

A classe dominante se reproduz enquanto tal e legitima sua dominação, sobretudo, através do poder simbólico do qual dispõe. É na esfera simbólica ${ }^{6}$ que atuam mecanismos sutis de dissimulação e de

5 Vale dizer (BOURDIEU, 2001) que os todos os três tipos de capitais, isto é, o social, o cultural e o econômico, podem ser convertidos em capital simbólico. Este último é adquirido pela via da luta pelo reconhecimento, que confere o sentido da nossa existência. É a partir do olhar do outro, de sua aprovação, do seu amor, do seu respeito que experimentamos nossa existência social. É uma luta contra os outros, mas, sobretudo, com estes outros sem os quais não seria possível acumular capital simbólico.

${ }^{6}$ Pode-se perguntar se esse raciocínio não se casa com as concepções de ideologia de Karl Marx, ou com as concepções de ideologia dos mais variados tipos, fornecidas principalmente pelos marxistas ao longo do século XX. No entanto, é importante mencionar que Bourdieu recusa o termo ideologia, pois, assim como Foucault, o considera um conceito problemático que se tornou generalizante em demasia; 
transfiguração, capazes de esconder os interesses que estão em jogo. Os sistemas simbólicos (arte, ciência, religião etc.) estão impregnados por uma lógica, que favorece os dominantes e que sujeitam os dominados. Estes últimos reconhecem e legitimam o poder simbólico da classe dominante. É esta adesão tácita, não consciente, dos dominados à lógica dominante, apenas cedida graças ao trabalho simbólico de inculcação de pressupostos não questionados, dissimulados e transfigurados como evidentes em si mesmos, que Bourdieu designa como violência simbólica. (BOURDIEU, 1989; 2001; 2002; 2015).

Esse mascaramento do real sentido da dominação está presente, por exemplo, na crença, mesmo entre os mais desabonados, em que a única causa das desigualdades sociais são os méritos e capacidades individuais ou que cada um só deve ascender e, de fato, só ascende na pirâmide social graças ao seu próprio esforço7. O que implica em dizer que a violência simbólica (BOURDIEU, 2001) apenas acontece quando há adesão dos dominados, portanto, a própria incorporação pelos dominados da cultura dominante, quando os dominados não possuem outros instrumentos de conhecimento prático que não aqueles da própria ordem que os sujeita.

Não se trata, no entanto, de algo passível de ser transformado meramente pela decisão da vontade consciente ou por uma simples tomada de consciência. Como o próprio Bourdieu (2001) desenvolve em Meditações Pascalianas, momento mais maduro de sua obra, é-se necessário mais do que o conhecimento teórico acerca dos efeitos da dominação para que haja uma desestruturação radical do habitus dominado, porque este não se reduz a ideias ou representações, mas também, e, sobretudo, tem a ver com disposições afetivas, maneiras de ser e de sentir aquém do nível da consciência ${ }^{8}$, inscritas duravelmente nos corpos, que se manifestam, inclusive, na héxis corporal.

abrangendo mais do que deveria e explicando pouca coisa, carecendo de uma estabilidade. Se Bourdieu opta por poder simbólico, Foucault opta por falar em discurso, poder-saber e outros conceitos que ambos os autores consideravam mais específicos e mais precisos do que o conceito de ideologia da teoria marxiana ou das teorias marxistas (GIDDENS; SUTTON, 2017).

7 Bourdieu (2015, p.231-267) analisou como a ação pedagógica rotinizada tende a "selecionar" estatisticamente somente aqueles que já estão pré-dispostos a ter uma vida escolar bem-sucedida em razão de um habitus cultivado originário, adquirido em convívio familiar, isto é, com esquemas cognitivos compatíveis com o que é exigido pelo sistema de ensino. No entanto, a ideologia do dom ou do mérito é propagada pela Escola como meio de justificar os seus procedimentos de seleção como neutros e não problematizar as imensas desigualdades sociais que condicionam as trajetórias escolares dos diferentes grupos sociais.

${ }_{8}^{8}$ Esta é uma marca distintiva entre o conceito de habitus adotado por Bourdieu (2001) e o conceito de ideologia, pois este último pressupõe que a dominação simbólica se assenta meramente em um conjunto de representações bem definidas e bem dispostas na consciência do sujeito e que bastaria a este desvelá-lo para se lhe emancipar. Por esta razão, Bourdieu cada vez menos passou a se utilizar da noção de ideologia, que costumava 
$\mathrm{Na}$ introdução à edição brasileira de Um esboço da teoria da prática, Renato Ortiz (1983), sintetiza algumas limitações referentes ao pensamento bourdieusiano como a ênfase excessiva no circuito da reprodução das desigualdades sociais e, portanto, com uma tendência a subestimar o potencial de transformação e resistência por parte dos grupos oprimidos. Dessa maneira, a seu ver, Bourdieu retira a história de seu curso, apenas enxergando continuidades onde poderia ter havido uma ruptura real. Para Ortiz (1983), Bourdieu não demonstra como o habitus dominado poderia de fato passar por um processo de desestruturação. Vale salientar, contudo, que esta crítica é anterior à publicação de Meditações pascalianas, obra na qual, Bourdieu abre um espaço maior ao tema da resistência.

J. Manuel Fernández (2005), entretanto, em um artigo mais recente, afirma que Bourdieu não desconsidera a existência de formas complexas de resistência, mas enfatiza a permanência de disposições duráveis do habitus dominado inscritas na héxis corporal mesmo contra a vontade daqueles que as portam. A este respeito é interessante notar o papel que Bourdieu concede à resistência em Meditações pascalianas. Ele ressalta que uma luta simbólica que seja travada apenas no campo das ideias não tem eficácia real sobre o mundo social, porque seus partidários, por acreditarem cegamente na intervenção performática da linguagem, compreendida em si mesma como forma de resistência, esquecem-se de que a realidade não é mero efeito da linguagem, que possa ser desfeita por um enunciado, mas fruto da dialética entre habitus e campo, que faz coincidir as estruturas cognitivas e sociais.

Dessa forma, postula que, apenas em momentos de crise social, política ou econômica, pode-se fazer uso com eficiência da frustração resultante da defasagem entre expectativas coletivas e oportunidades reais para efetivar uma transformação sensível das relações força ou, então, para mudar significativamente os parâmetros de redistribuição das riquezas em favor dos mais pobres. Os porta-vozes intelectuais ou políticos progressistas, nesse contexto, sendo capazes de dar uma expressão simbólica e discursiva, através do poder simbólico do qual são portadores, a um desejo popular de mudança tornada possível porque o habitus não é composto primordialmente por representações e ideias bem formadas, mas por sentimentos e orientações práticas para a ação imediata e, portanto, com uma parcela de indeterminação.

As revoluções simbólicas, para Bourdieu (2001), só acontecem e podem acontecer dentro de um espaço dos possíveis, de potencialidades objetivas, inscritas na própria estrutura do campo ou da sociedade mais 
ampla, vislumbradas pelos agentes que desejam operar uma subversão simbólica das relações de força e das relações simbólicas de força. Contudo, a própria capacidade para vislumbrar e desejar uma transformação é condicionada pelos habitus adquiridos pelos agentes em sua história e trajetória social. Apenas um agente que ocupe uma posição em falso em relação ao campo de forças atual, quer porque detenha um habitus defasado com relação às estruturas objetivas e deseja assim um "retorno ao passado", quer em razão de disposições revolucionárias, que se orientam para o futuro, é efetivamente disposto a efetuar e lutar por mudanças.

Na luta simbólica pelos princípios de definição do mundo social, caberia aos intelectuais, políticos e ativistas mobilizar e capitalizar a frustração das massas nos momentos de crise emprestando-lhes seu capital cultural. Esta aliança temporária se fundaria em uma homologia parcial entre a posição dominada dentro do campo intelectual e político que ocupariam estes porta-vozes e aquela ocupada pelos grupos dominados na sociedade como um todo. Corre, no entanto, esta aliança o risco de se desfazer ou desestabilizar em função da correspondência imperfeita de interesses entre esses grupos distintos.

A despeito de todas as limitações apontadas por Bourdieu (2001) com relação ao potencial de transformação e resistência mediante o poder simbólico nos parece que é somente através dele e da mediação dos intelectuais e demais detentores de capital cultural, que o autor enxerga a possibilidade de revolução das estruturas sociais e cognitivas. Bourdieu, é verdade, enfatiza a histerese da ordem social, das formas duráveis de violência simbólica, até mesmo quando há um esforço consciente para desfazê-las.

De fato, acreditamos que, por mais que haja resistência, a cultura dominante age com violência sobre os corpos daqueles que a rejeitam, já que são excluídos de certos espaços, insultados e marcados por certos estigmas, consequentemente a dimensão simbólica não pode ser dissociada da materialidade da vida, do corpo. Violência que não se restringe aos efeitos do consentimento tácito à dominação, embora Bourdieu (1989; 2001; 2002; 2015) sempre o presuma quando se refere à violência simbólica.

O que queremos discutir aqui é que há uma violência no próprio ato de estigmatizar que prescinde da adesão consciente ou não, do reconhecimento e desconhecimento do estigmatizado. Violência que se expressa por meio da linguagem e que se vale dos mecanismos do poder simbólico, isto é, os de transfiguração e dissimulação. Estigmatizar aqueles que resistem à dominação e a sua resistência constitui uma estratégia do poder simbólico para desqualificar seus oponentes. 
Podemos, portanto, pensar com o auxílio do sociólogo canadense Erving Goffman (1988) que há a violência da projeção de uma identidade social virtual, que algumas vezes não corresponde à identidade social real. A identidade é definida em termos "intragrupais" e "extragrupais". Se, de repente, alguém, que constrói sua identidade, em parte, no interior de dado grupo social, é estigmatizado por não estar de acordo com a identidade social definida pelos padrões dominantes, esta pessoa está sofrendo um tipo de violência decorrente do fato do outro, alguém de fora do seu grupo, querer reduzi-la a uma identidade previamente estabelecida pelo seu universo cognitivo e cultural. Uma violência simbólica que desconsidera sua diferença e sua identidade social real.

Goffman (1988), em sua obra "Estigma", pensa os processos de socialização do estigma como divididos entre um primeiro momento de socialização, em que o indivíduo estigmatizado incorpora o ponto de vista dos "normais"9 e em um momento posterior em que ele descobre como é a experiência de possuir um estigma. Alguns sujeitos adquirem um estigma mais tarde durante a vida em contraposição àqueles que já nascem. Existem os estigmas das abominações e deformidades corporais, os estigmas moralmente imputáveis e aqueles que são tribais.

Um estigma da ordem da moral, por exemplo, é, muitas vezes, não evidente e passível de ser escondido, além de ser adquirido e não congênito. Nesse sentido, por exemplo, um sujeito aleatório muito provavelmente, foi socializado durante sua infância e/ou adolescência para ser heterossexual e, no entanto, mais tarde, quando se percebe homossexual, descobre como é ser estigmatizado se, por acaso, essa informação for tornada pública ${ }^{10}$.

Com a ajuda de Bourdieu (1989; 2001; 2002; 2015), podemos supor que o habitus dominado adquirido em um primeiro momento da socialização não desaparece completamente da personalidade, ao menos, do inconsciente do sujeito estigmatizado, que rejeita os parâmetros de classificação da cultura dominante. Podemos nomear esta ambiguidade de disposições como o fez Bourdieu (2001) de habitus contraditório fundado em uma "fratura do eu".

Há a possibilidade assim em que a relação, por exemplo, entre um homem machista e uma mulher feminista não esteja desprovida de dominação simbólica ${ }^{11}$, à medida que esta faça algumas concessões ou,

9 Goffman, para efeitos de análise, distingue, em termos relacionais, o normal do estigmatizado, em que o primeiro é aquele que não possui um estigma em relação àquele que o possui.

${ }^{10}$ Exemplo dado pelo próprio Goffman (1988).

${ }^{11}$ Em A dominação masculina (2002) Bourdieu discute a organização social de gênero da sociedade cabila para realizar uma espécie de arqueologia de nosso inconsciente histórico a fim de entender a dominação simbólica dos homens sobre as mulheres. Nesta obra, o autor destaca que as mulheres incorporam esquemas de ação e percepção androcêntricos 
ainda que resista, sinta-se, de alguma maneira, inferiorizada e agredida pelo insulto perpetrado pelo estigma. Dito de outro modo, um novo habitus feminista pode coexistir com resíduos de um habitus dominado anterior.

Além disso, é necessário reforçar que os indivíduos estigmatizados, ainda que não incorporem o ponto de vista dos "normais", não deixam de ser violentados pela projeção do estigma imputado. Projeção que só se torna possível à medida que o poder simbólico, não mais apenas entendido como recurso de inculcação e incorporação da cultura dominante, mas igualmente como a própria sanção ou punição àqueles que se desviam dos parâmetros estabelecidos, em seu jogo de disputa simbólica, contraatacam a resistência com o artifício do estigma.

Sob esse ponto de vista, a violência simbólica, a nosso ver, funciona em duas dimensões: uma subjetiva e outra objetiva, porque ainda que não esteja incorporada sob a forma de um habitus dominado ela se encontra objetivamente presente no leque de representações culturais degradantes, que são acionadas para estigmatizar a resistência. As consequências subjetivas são potenciais e prováveis, podendo-se com frequência resvalar numa violência psicológica, com as sequelas correspondentes.

É evidente que a adesão tácita da sociedade envolvente e de suas instituições à lógica dominante constitui-se como pré-requisito no plano macroscópico para que se tenha eficácia simbólica nessa espécie de violência no nível microscópico. Em outros termos, a violência está presente na cultura e nas instituições sociais, mas se corporifica e se reatualiza nas relações sociais entre sujeitos, que podem ou não compartilhar os mesmos pressupostos tácitos, ainda que seja necessário que a categoria social a que o sujeito estigmatizado pertença: negros, mulheres, LGBTs, deficientes etc. enquanto grupo marginalizado e dominado, estatisticamente se submeta à lógica da dominação como garantia e condição mesma da reprodução da ordem simbólica.

A grande contribuição de Saffioti (2004), para este nosso entendimento, é que ela pensa em termos de processos micro e processos macro interdependentes, um sendo o avesso do outro. Neste entrelaçamento entre micro e macro, propomos pensar que a violência simbólica funciona ao mesmo tempo enquanto fenômeno "objetivo" e "subjetivo". Enquanto fenômeno social inscrito na objetividade, prescinde da aceitação consciente ou inconsciente extraída de um sujeito particular. No entanto, a alquimia sociossimbólica da realização de categorias (WACQUANT, 2013), que torna realidades sociais concretas, inscritos em

que legitimam a violência simbólica de que são alvo. Dessa forma, chegamos à conclusão que para Bourdieu (2002) a dominação simbólica não é apenas da ordem da dominação de classe, mas também potencialmente de qualquer grupo social dominante sobre outro. 
estruturas objetivas, constructos mentais, somente acontece mediante a adesão estatística dos dominados. Já como fenômeno "subjetivo" consiste na incorporação da violência simbólica, como "interiorização da exterioridade".

Imaginamos também uma relação intersubjetiva na qual não haja uma reciprocidade dos instrumentos de conhecimento prático utilizados pelos envolvidos e, portanto, aquele que estigmatiza não consegue extorquir a aceitação tácita do estigmatizado. Mesmo nessa situação hipotética, a violência simbólica continua a operar pela ação do estigma.

De todo modo, o fato é que toda e qualquer violência objetiva, sistêmica ou simbólica, incide sobre os corpos, os molda, os sujeita ou os exclui. Na impossibilidade de "assimilar", extraindo-lhes sua aceitação, aqueles que a ela resistem, ainda assim, a violência simbólica lhes imporá sanções simbólicas e materiais, excluindo-os de certos espaços e direitos, determinando onde podem falar e frequentar e mesmo que desafiem essas fronteiras arcarão com as consequências.

Nesse sentido, nos é possível pensar, com alguma liberdade, em uma violência simbólica em sentido ampliado em relação ao proposto por Bourdieu (1989; 2001; 2002; 2015). O poder simbólico da cultura dominante convive com a resistência de grupos minoritários, que resolvem lutar por outra definição do mundo social. Este poder não é passivo à resistência. Toda luta implica em revanches e em contra-ataques. O poder simbólico, ao não realizar seu projeto de captura de todos os corpos, ao não inculcar em todos eles as bases de sua legitimação, articula-se na base da linguagem e dos sistemas simbólicos como a religião e a ciência, para dar a sanção aos revoltosos, incutindo-lhe estigmas determinados.

As sanções simbólicas como denominadas por Bourdieu (1989; 2015) àqueles que resistem à dominação e que desejam operar uma subversão simbólica do mundo social não precisam ser pensadas como uma modalidade à parte da violência simbólica, pois isto significaria deixar escapar a real amplitude da dependência constitutiva entre poder e resistência, pois a resistência "obriga" o poder a se reinventar e, por esta via, a renovar as formas de violência. Foucault (2014), para quem o problema da resistência era mais presente do que para Bourdieu - este mais preocupado com o problema da reprodução das desigualdades sociais, em sua caracterização do poder sempre o definia em relação à resistência como elemento consubstancial à sua analítica, formando o binômio: poder-resistência. De outro modo, quando esta última não estava presente, o autor não falava em relação de "poder”, mas de “coação".

Em suma, o nosso ponto é que a violência simbólica pode ser compreendida tanto como a subjetivação da cultura dominante (uma espécie de violência invisível pela sua característica de legitimar a 
dominação através de procedimentos ideológicos de transfiguração e dissimulação), como a ação igualmente ideológica de estigmatizar sujeitos e grupos que resistem aos princípios dominantes de hierarquização do mundo social com potencial para degradá-los subjetiva e objetivamente.

\section{Considerações finais}

Tivemos como meta discutir criticamente o conceito de violência simbólica a partir de um referencial teórico interdisciplinar, bem como a partir de uma compreensão dialética das totalidades sociais. Para atingirmos nosso objetivo, nos questionamos primeiramente sobre o que é a violência. Mostramos no primeiro tópico a necessidade de se articular não hierarquicamente fatores simbólicos e materiais, objetivos e subjetivos, "naturais" e culturais a fim de tornar a teoria mais próxima dos complexos heterogêneos e orgânicos que compõem a vida social e, dessa forma, do fenômeno da violência em sua complexidade.

Feita esta primeira abertura cognitiva, nos debruçamos na discussão propriamente dita da violência simbólica tal como formulada por Bourdieu $(1989 ; 2001 ; 2002 ; 2015)$. A violência simbólica, como discutimos, tende a velar e a tornar invisíveis os fundamentos reais da dominação, mas isto não significa que no próprio interior da dinâmica de dominação não haja outros vetores de subjetivação operando, pois aquela não é absoluta. A resistência é parte constitutiva das relações de poder, quer se tenha consciência ou não das opressões sociais.

Diante disso, as sanções simbólicas às quais Bourdieu (1989; 2015) se refere, quando alude à luta simbólica pela definição dos parâmetros de classificação do mundo social, não possuem necessariamente uma qualidade distinta da própria violência simbólica, mas se constituem como mais uma das suas possibilidades.

Nos jogos de poder, os artifícios de dissimulação e transfiguração do poder simbólico contra-atacam a resistência com a ação ideológica do estigma e, por esta via, degradam objetiva (nas representações culturais) e subjetivamente (danos psicológicos) os alvos que lhe resistem, tendo sido eles, em sua maioria, socializados pela cultura dominante ainda na primeira infância e isto subsiste mesmo que de maneira parcial em seus inconscientes ${ }^{12}$. Todavia, mesmo na situação hipotética, na qual não haja adesão inconsciente por parte do estigmatizado, a violência simbólica atua e permanece como projeção violenta do estigma - com consequências materiais e simbólicas para a sua vítima.

12 Descartar como os ecos da infância reverberam na constituição dos sujeitos seria uma intransigência de algo reconhecido não somente pela escola psicanalítica, mas das demais escolas do campo da psicologia, como a psicologia comportamental e o cognitivismo. 
Forma de violência de natureza simbólica, que continua a operar deslocamentos e inversões, que pretendem sujeitar aqueles que se recusam a ser sujeitados. Assim, para ilustrarmos o que estamos a tentar dizer da forma mais objetiva que a linguagem nos permite: mulheres que se posicionam como feministas podem ser retratadas como mal-amadas e ressentidas, negros que ocupam espaços antes destinados apenas a brancos, como a universidade, podem ser descriminados e inferiorizados pela alegação que apenas passaram em função das cotas raciais, pessoas da comunidade LGBT envolvidas com a ação política podem ser acusadas de fazer lavagem cerebral nas crianças e adolescentes ou serem vistas como “doentes" e "degeneradas".

\section{Referências bibliográficas}

BOURDIEU, P. A dominação masculina. Rio de Janeiro: Bertrand Brasil, 2002.

. A economia das trocas simbólicas. São Paulo: Perspectiva, 2015

. O poder simbólico. Rio de Janeiro: Bertrand Brasil, 1989.

. Meditações pascalianas. Rio de Janeiro: Bertrand Brasil, 2001.

. Um esboço da teoria da prática. São Paulo: Ática, 1983.

CHAMAYOU, G. A teoria do drone. São Paulo: Cosac Naï, 2015.

ELIAS, N. O processo civilizador: uma história dos costumes. Rio de Janeiro: Zahar, 1996.

FERNÁNDEZ, J. M. La noción de violencia simbólica en la obra de Pierre Bourdieu: una aproximación crítica. Cuadernos de Trabajo Social, Madrid, n. 7, v. 18, p. 7-31, jun. 2005.

FOUCAULT, M. Microfísica do poder. São Paulo/Rio de Janeiro: Paz e Terra, 2014.

. A história da sexualidade: A vontade de saber. Rio de Janeiro:

Paz e Terra, 2017.

FREUD, S. O mal-estar na cultura. São Paulo: L\&PM Editora, 2010.

GIRARD, R. A violência e o sagrado. Rio de Janeiro/São Paulo: Editora Paz e Terra, 1990.

GOFFMAN, E. Estigma: notas sobre a manipulação da identidade deteriorada. Rio de Janeiro: LTC - Livros Técnicos e Científicos Editora SA, 1988.

GIDDENS, A.; SUTTON, P. W. Conceitos essenciais da sociologia. 2. ed. São Paulo: Editora Unesp, 2017.

MARTUCCELLI, D. Reflexões sobre a violência na condição moderna. Tempo Social, 11(1), 157-75, 1999.

MICHAUD, Y. A violência. São Paulo: Editora Ática, 2001. 
SAFFIOTI, H. I. B. Gênero, patriarcado, violência. São Paulo: Editora Fundação Perseu Abramo, 2004.

WACQUANT, Loïc. Poder simbólico e fabricação de grupos: como Bourdieu reformula a questão das classes. Novos estud. - Cebrap, São Paulo, n. 96, pp. 87-103, jul. 2013.

ŽIŽEK, S. Violência: seis reflexões laterais. Trad. Miguel Serras Pereira. São Paulo: Boitempo, 2014.

Como citar:

BEZERRA, Lorena Karla Costa; BARROS, Rodrigo José Fernandes de. Um olhar possível sobre a violência simbólica. Verinotio - Revista on-line de Filosofia e Ciências Humanas, Rio das Ostras, v. 25, n. 1, pp. 284-302, abr. 2019.

Data de envio: 12 ago. 2018

Data de aceite: 25 mar. 2019 